\title{
DEFORMATION OF TITANIUM BY THE HIGH PRESSURE TORSION METHOD
}

\author{
${ }^{1}$ Irina VOLOKITINA, ${ }^{1}$ Andrey VOLOKITIN, ${ }^{1}$ Yevgeniy PANIN, ${ }^{1}$ Marina LATYPOVA \\ ${ }^{1}$ Karaganda state industrial university,Temirtau, Kazakhstan, dyusha.vav@mail.ru
}

https://doi.org/10.37904/metal.2020.3475

\begin{abstract}
This work is devoted to one of the most important problems of modern physics of strength and plasticity - to the behavior of metals under various conditions of intense external influences. These are large plastic deformations, the formation of nanocrystalline structures under these conditions, complex cooperative dynamic processes in the zones of deformation localization, low temperatures or high deformation rates, highstrength materials, etc. The relevance of this problem is due to the use of intensive external influences in numerous new technologies for obtaining and processing metal materials. To implement the high-pressure torsion process on a hydraulic single-column press, a special design matrix has been developed that allows the high-pressure torsion process to be implemented due to the linear movement of the striker relative to the frame. For investigation of this process, a FEM simulation using Deform program was used. Results of the study of the strain state showed that after 10 deformation cycles the average strain value is about 3,8 . Results of the study of the stress state showed that compressive stresses prevail in the deformation zone. The tensile stresses are concentrated mainly on the periphery of the workpiece, its value is about $1080 \mathrm{MPa}$. Despite of high level of tensile stresses the value of compressive stresses is more than 3 times.
\end{abstract}

Keywords: Severe plastic deformation, titanium, high pressure torsion, matrix, stress-strain state, FEM

\section{INTRODUCTION}

The development of metal forming technologies is now becoming one of the most important factors for improving the efficiency of industrial production. The development of metal forming is impossible without the development of fundamentally new technologies and equipment that allow you to obtain high-quality products at the lowest cost of their production. Also, in the conditions of market relations, it should be taken into account that the factor of high quality of metallurgical products directly affects the competitiveness, and, consequently, the increase in the welfare and functioning of an industrial enterprise. Obtaining high-quality products, i.e. products that fully meet the needs of the consumer, realize the greatest economic effect and have the highest technical, economic and operational indicators, in the metallurgical and machine-building industry is mainly associated with the development of new technological processes.

One of the approaches developed in recent years to achieve high strength properties in metals and alloys is the formation of ultra-fine-grained or nanostructured states under plastic deformation. It was found that a combination of two factors leads to the production of ultra-fine-grained and nanostructure. This is a high intensity and significant non-monotonicity of deformation performed at temperatures no higher than the temperature of the return process. The first process provides the necessary dislocations generation and the dislocation structure evolution, and the second process provides the activation of new sliding systems of lattice dislocations and their interaction with the small-angle fragment boundaries formed during deformation, which leads to their restructuring into high-angle boundaries of a general type. It is also necessary to have a high hydrostatic pressure, which is necessary to prevent the formation of cracks and pores.

Various methods and schemes of plastic deformation are used to obtain ultra-fine-grained or nanostructured states: all-round forging, rolling, equal-channel angular pressing, high-pressure torsion, etc. [1-3]. Each of them 
can lead to a significant increase in the strength of the material [5-6] while maintaining a certain margin of plasticity. It is known that severe plastic deformation by high pressure torsion (HPT) allows achieving the highest degrees of deformation in materials and grain grinding up to nanocrystalline sizes [4-5]. Therefore, the high pressure torsion method was chosen for titanium deformation, which will allow to achieve the maximum degrees of grinding of the grain structure of titanium by applying ultra-large degrees of shear deformation under high applied pressure.

High-pressure torsion was first used for processing metal materials by P. Bridgman in 1935 [6]. The method received its second birth thanks to the work of Russian scientists in the 70-90-ies of the last century, in which it was used to obtain the NS states of many pure metals, alloys, intermetallides and ceramics.

To implement the process of torsion under high pressure on the existing equipment of the University laboratory, a matrix of a special design was developed that allows to implement the high pressure torsion process, due to the linear movement of the striker relative to the frame (Figure 1).

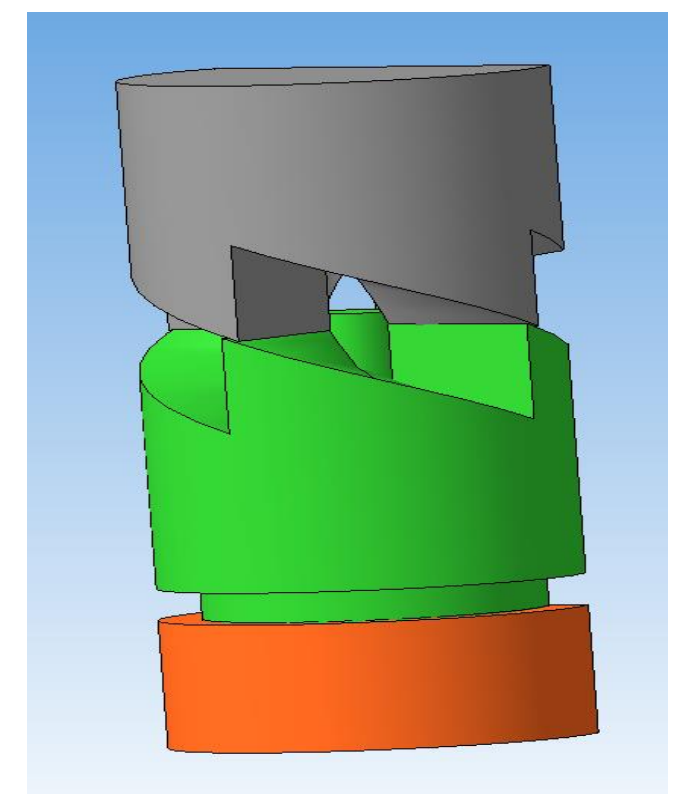

Figure 1 Model of high pressure torsion matrix

The linear movement of the upper striker, with the upper part of the matrix fixed on it, due to the contact friction forces directed at an inclined angle to the opposite part of the matrix, transmits a torque to it, resulting in a linear movement turns into a torsion movement.

The matrix consists of three parts. The lower part, which is a fixed matrix in which the sample is placed in the form of a disk with a diameter of $30 \mathrm{~mm}$ and a thickness of $10 \mathrm{~mm}$. A rotating part of the matrix that has a lower flat surface in contact with the workpiece. And the upper surface, which is a spiral shape consisting of four segments. The upper part of the matrix is fixed in the upper striker, which also has a spiral shape, consisting of four segments.

At the initial moment, the segments are separated, then the upper and lower parts of the matrix converge. Due to the segments of the matrix located at an acute angle and a spiral shape, the central part of the matrix is twisted and pressure is directly applied to the sample.

\section{FEM SIMULATION}

To test the implementation of the proposed method, it was modeled in the Deform 3D package, which allowed us to identify the "weak points" of the process, evaluate the stress-strain state of the workpiece at each cycle, 
the strain intensity obtained during one full cycle of this method, as well as the required deformation force. All of these factors needed to assess the implementation of the method and the design of tooling, selection of power equipment for the experiment, on the basis of which to judge the degree of changes in the structure of the workpiece material.

The stress-strain state (SSS) during deformation was analyzed based on the distribution of next parameters:

1) effective strain;

2) effective stress;

3) hydrostatic pressure (stress mean).

A titanium disk with a diameter of $30 \mathrm{~mm}$ and a thickness of $10 \mathrm{~mm}$ was used as the initial blank. The deformation was performed at room temperature.

\section{RESULTS AND DISCUSSION}

\subsection{Strain state}

The results of the effective strain distribution during high pressure torsion are shown in Figure 2.

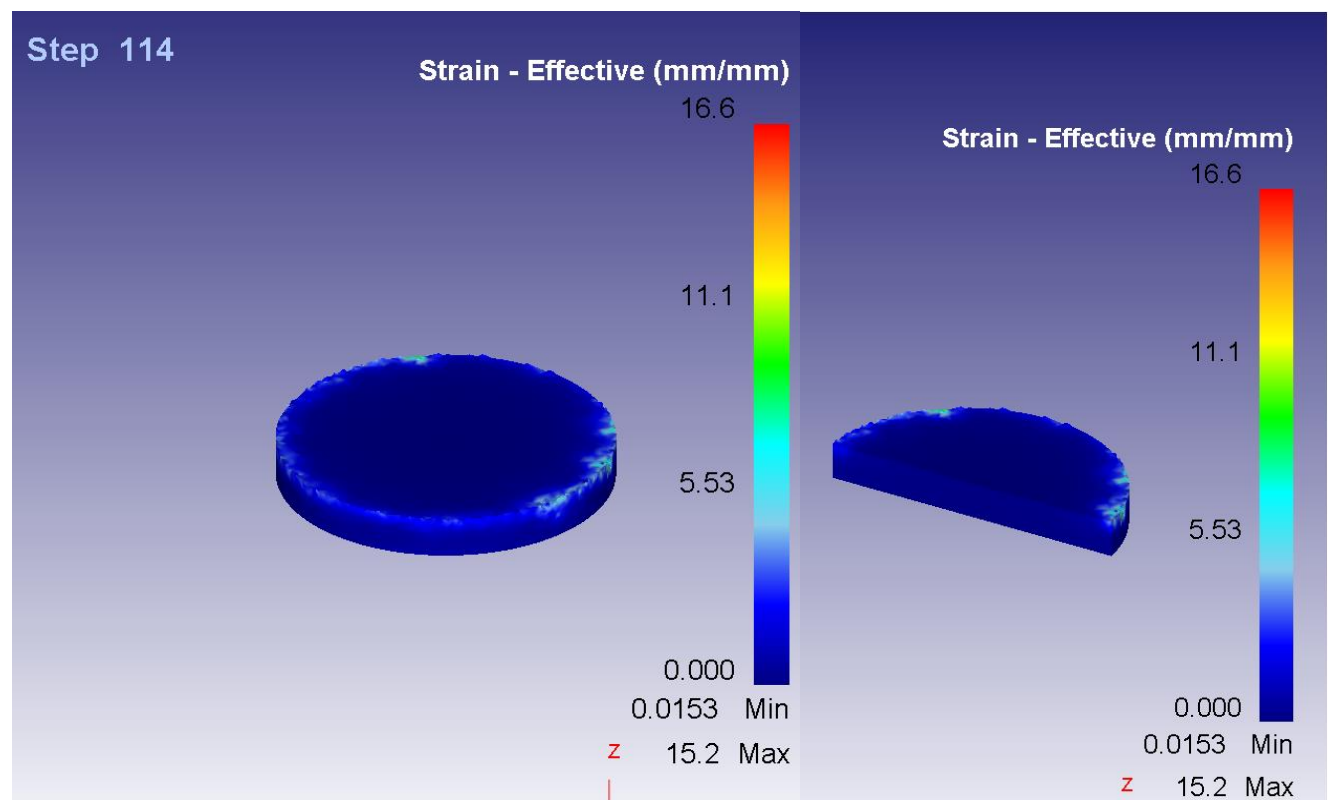

Figure 2 Distribution of effective strain across the workpiece section

Based on the obtained data, it is established that during the deformation process, the highest effective strain is observed along the contours of the workpiece, which is explained by the influence of external friction forces. Analyzing the sections of the obtained samples, it was found that the strain distribution over the entire volume of the deformed billet is very uniform. Moreover, the strain degree of the inner layers does not differ from the degree of deformation of the surface layers-this can be judged by the uniform color of the inner and outer layers on the section. So, after 10 deformation cycles the average strain value is about 3,8 .

\subsection{Stress state}

The stress state of the workpiece at the time of deformation is the most important characteristic that affects the production of high-quality metal. The results of the distribution of equivalent stress at HPT are shown in Figure 3. 


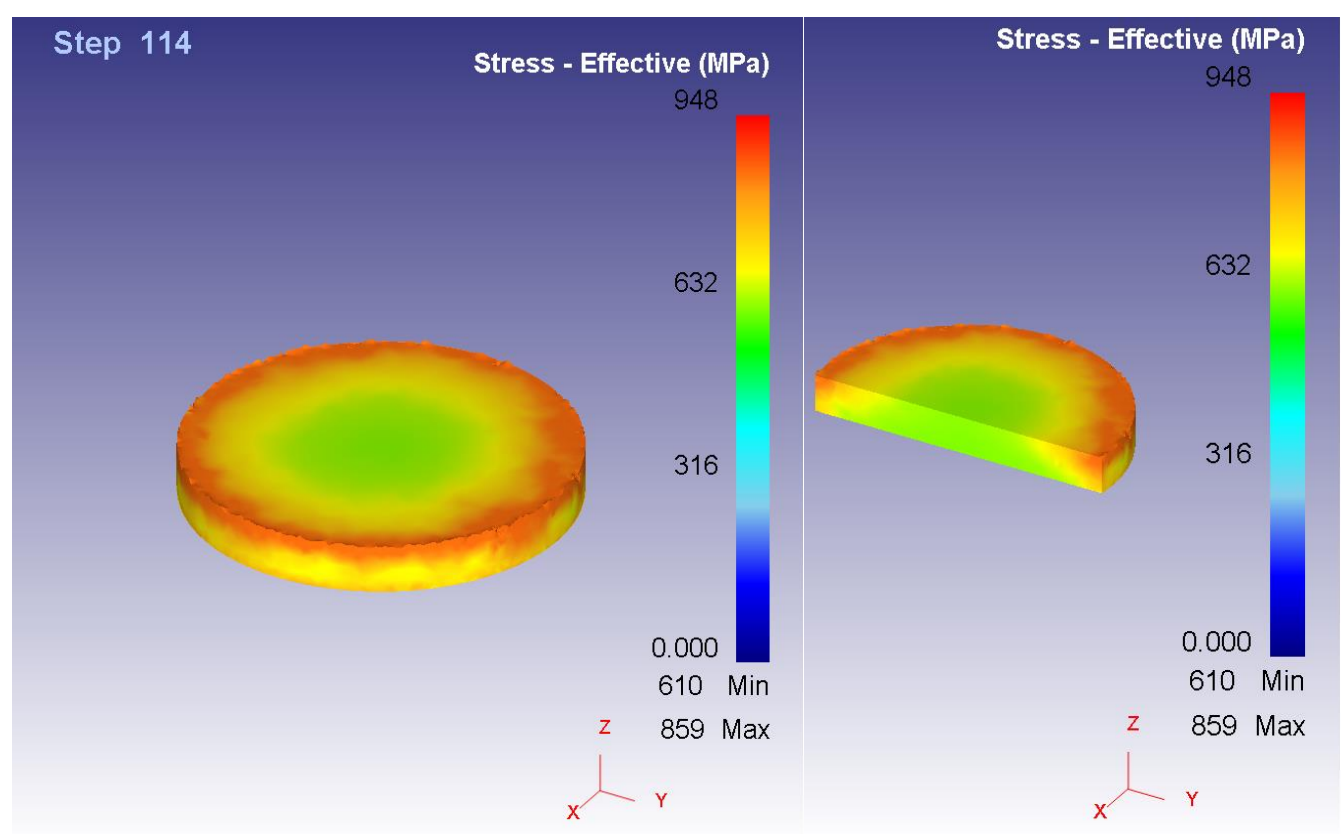

Figure 3 Distribution of equivalent stress across the workpiece section

The equivalent stress covers the entire deformation zone and reaches a value of up to $450 \mathrm{MPa}$ in the central layers of workpiece and up to $630 \mathrm{MPa}$ in the outer layers.

An important factor that has a significant impact on the efficiency of structure formation, especially for lowplastic and hard deformable materials, such as titanium, is the value of hydrostatic pressure. Applying hydrostatic pressure provides a high uniformity of stress, strain and structural state distribution, contributes to the creation of favorable contact friction conditions, and preserves the plasticity resource.

The best processing of the cast structure and closing of internal defects is positively affected by the presence of compressive stresses inside the deformable body that occur during the pressing process. These stresses can be characterized by the hydrostatic pressure distribution in the cross section of the workpiece (Figure 4).

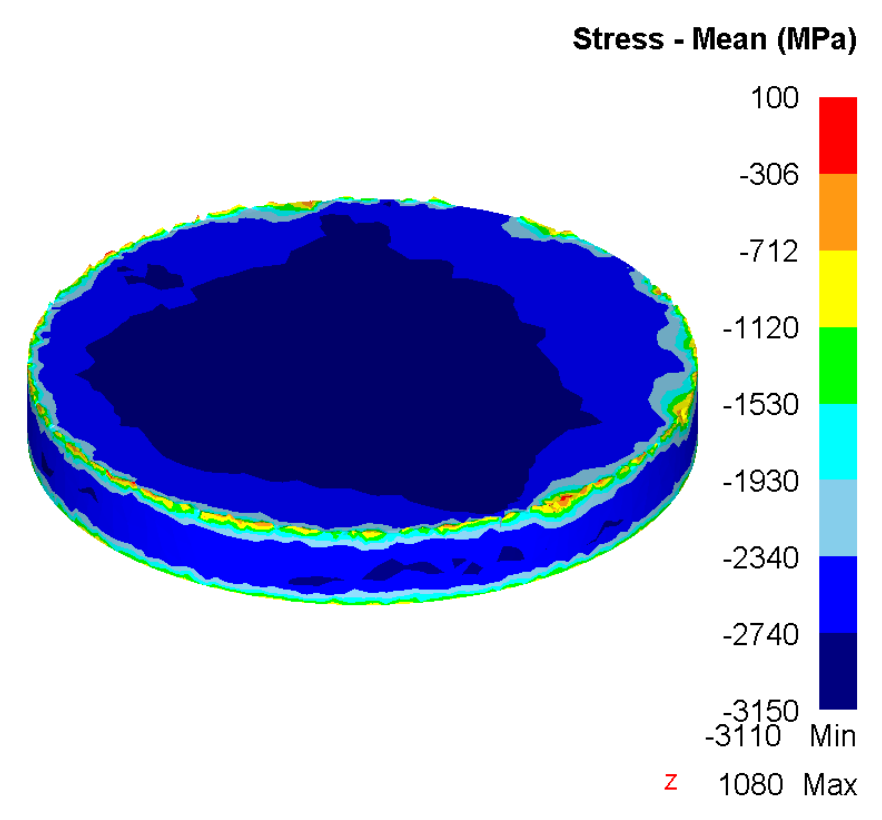

Figure 4 Distribution of the hydrostatic pressure 
More than the absolute value of the compression pressure (negative hydrostatic pressure), the higher ductility and smaller role in the scheme played by the principal stresses tensile stresses, the greater the ability to plastic deformation manifests metal. High hydrostatic pressure significantly increases the deformability of materials. It is also known that high hydrostatic pressure activates dislocation sliding, suppresses the processes of return, and leads to fragmentation of the structure at lower deformation degrees.

The nature of the distribution shows that compressive stresses prevail in the deformation zone, with the exception of small zones. The maximum tensile stresses are no more than $1080 \mathrm{MPa}$, its distribution is concentrated mainly on the periphery of the workpiece. The value of compressive stresses is more than 3 times.

After analysis using the "Damage" tool, it was found that there is no danger of destruction of the workpiece even after ten deformation cycles.

To obtain an ultra-fine-grained structure, it was decided to carry out the deformation at room temperature, but in the deformation process of due to friction forces, the workpiece is heated to a temperature of $135^{\circ} \mathrm{C}$. Cold high pressure torsion is accompanied by the release of a large amount of heat and an increase in the material temperature in the deformation zone. During the deformation process, heat is released due to internal friction (plastic deformation, which results in the friction of some parts of the metal against others). About $85 \%$ of the mechanical work used in torsion is spent on overcoming internal friction, and all the work of external friction is converted into heat.

For titanium, this heating will not lead to recrystallization, but will help partially relieve stress during deformation, which allows for a greater number of torsion cycles. After analyzing Figure 5, we can say that the heating of the workpiece occurs evenly across the entire section.

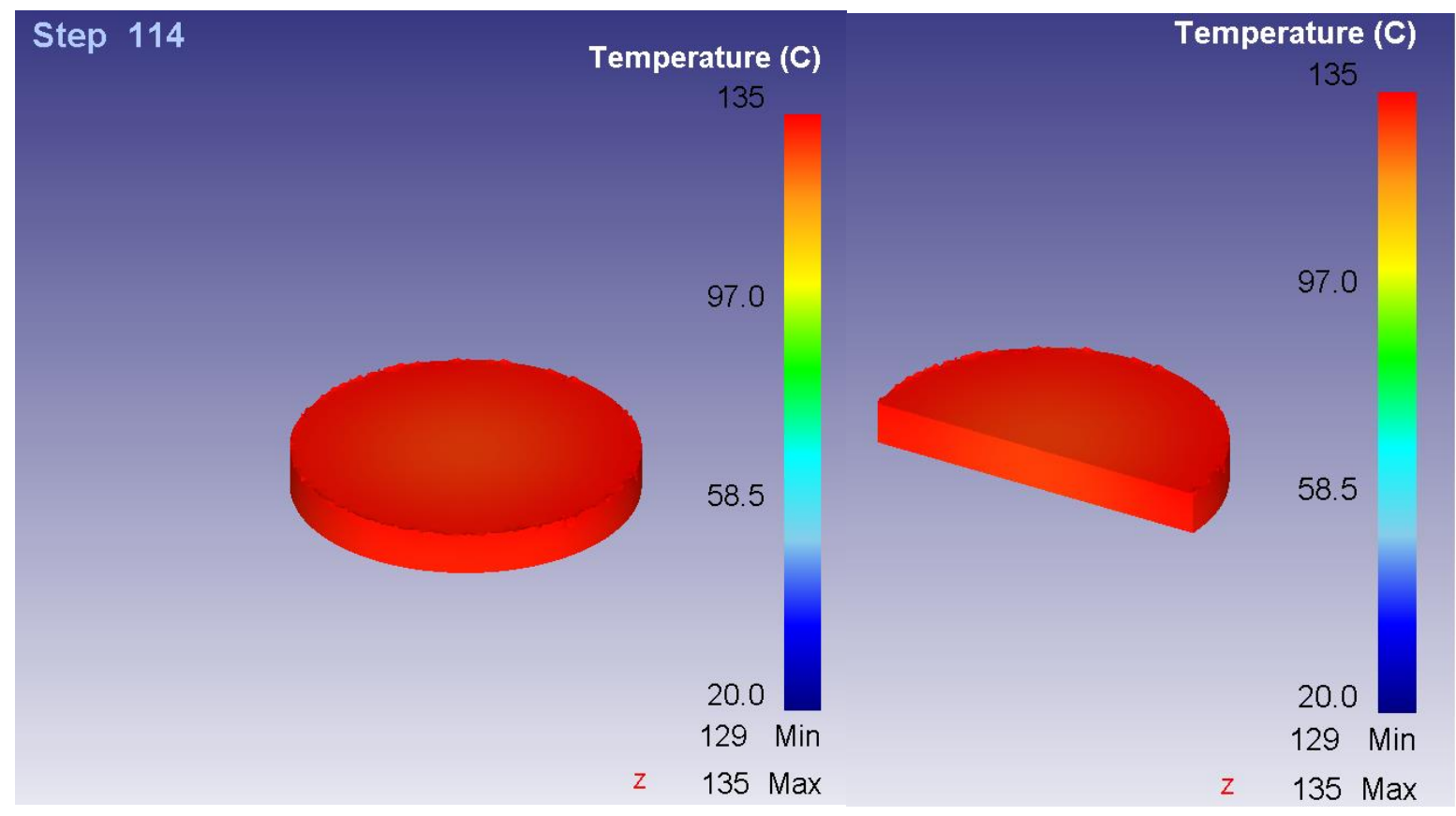

Figure 5 Temperature distribution across the workpiece section

When developing technological processes of metal forming and designing equipment, it is necessary to know the energy-power parameters of the process, in particular, the force that must be applied to the deformable body to overcome the metal's resistance to deformation and friction on the surface of the metal's contact with the tool. Consequently, the simulation results were used to plot the change in the strain force (Figure 6). 


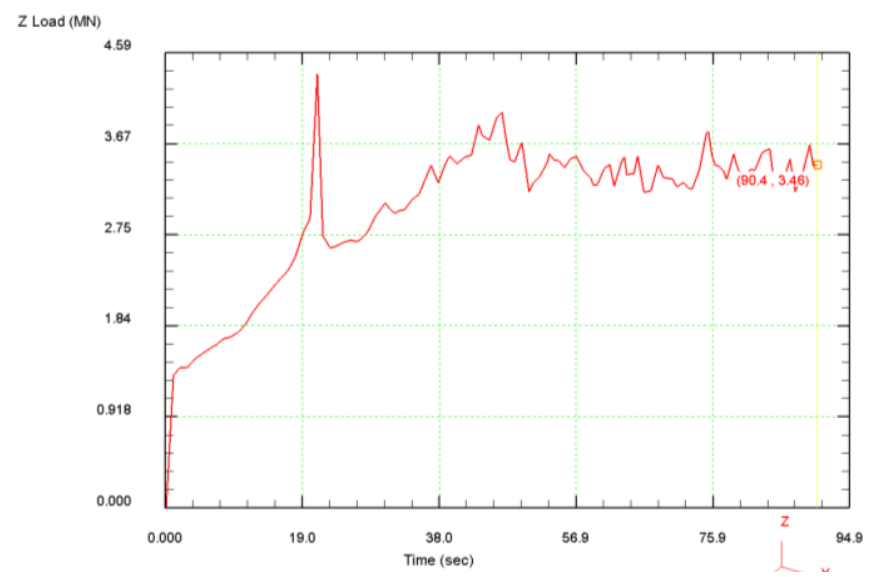

Figure 6 Value of the deformation force during high pressure torsion

Using studied process simulation, the strain force was estimated at about 3.5 MN. Analyzing the obtained results, a uniform increase in the deformation force is observed, which is explained by the plastic deformation of the sample, the degree of which reaches $1 \%$. The maximum peak stress corresponds to the maximum hardening of the sample. Further, a jump-like change in the deformation force associated with the material state under high pressure torsion is observed.

\section{CONCLUSION}

As a result of the simulation of deformation by the HPT method with the matrix of the new design, the following conclusions can be made:

- based on the stress-strain state analysis, the possibility of providing shear deformations in the processed metal is shown;

- $\quad$ strain state study showed that after 10 deformation cycles the average strain value is about 3,8 ;

- $\quad$ stress state study showed that compressive stresses prevail in the deformation zone. The tensile stresses are concentrated mainly on the periphery of the workpiece, its value is about $1080 \mathrm{MPa}$. Despite of high level of tensile stresses the value of compressive stresses is more than 3 times.

\section{REFERENCES}

[1] DU, Y., XU, H., ZHOU, Y., OUYANG, Y., JIN, Z. Phase equilibria of the Ni-Ti-Ta system at $927^{\circ} \mathrm{C}$. Materials Science and Engineering A. 2007, vol. 448, pp. 210-215.

[2] NAIZABEKOV, A., VOLOKITINA, I. Effect of the Initial Structural State of Cr-Mo High-Temperature Steel on Mechanical Properties after Equal-Channel Angular Pressing. Physics of Metals and Metallography. 2019, vol. 120, no. 2, pp. 177-183.

[3] GAZDER, A.A., DALLA TORRE, F., GU, C.F., DAVIES, C.H., PERELOMA, E.V. Microstructure and Texture Evolution of BCC and FCC Metals Subjected to Equal Channel Angular Extrusion. Materials Science and Engineering A. 2006, vol. 415, pp.126-139.

[4] HUANG, J., XU, Z. Evolution mechanism of grain refinement based on dynamic recrystallization in multiaxially forged austenite. Materials Letters. 2006, vol. 60, no. 15, pp.1854-1858.

[5] KHMELEVSKAYA, I.Yu., PROKOSHKIN, S.D., TRUBITSYNA, I.B. Structure and properties of Ti-Ni-based alloys after equal-channel angular pressing and high-pressure torsion. Materials Science and Engineering A. 2008, vol. 481-482, pp.119-122.

[6] MOUSUMI, D., GOUTAM, D., MAINAK, G., MATTHIAS, W., RAJNIKAN, V., GHOSH, C.S. Microstructures and mechanical properties of HPT processed 6063 Al alloy. Materials Science and Engineering A. 2012, vol. A558, pp. 525-532. 